\title{
Developing an approach for tourism climate change assessment: evidence from four contrasting Australian case studies
}

\author{
Stephen Turton ${ }^{\mathrm{a}^{*}}$, Tracey Dickson ${ }^{\mathrm{b}}$, Wade Hadwen ${ }^{\mathrm{c}}$, Bradley Jorgensen ${ }^{\mathrm{d}}$, \\ Tien Pham ${ }^{\mathrm{e}}$, David Simmons ${ }^{\mathrm{f}}$, Pascal Tremblay ${ }^{\mathrm{g}}$, Robyn Wilson ${ }^{\mathrm{a}}$ \\ ${ }^{a}$ School of Earth and Environmental Sciences, James Cook University, Cairns, \\ Australia; ${ }^{b}$ Centre for Tourism Research, University of Canberra, Canberra, \\ Australia; ' Australian Rivers Institute, Griffith University, Brisbane, Australia; \\ ${ }^{d}$ Centre for Sustainable Regional Communities, La Trobe University, Bendigo, \\ Australia; ; ${ }^{e}$ School of Economics, The University of Queensland, Brisbane, Australia \\ ${ }^{f}$ Sustainable Tourism Cooperative Research Centre Ltd, Griffith University, Gold \\ Coast, Australia; ${ }^{g}$ School for Social Policy and Research, Charles Darwin University, \\ Darwin, Australia.
}

*Corresponding author. Email: steve.turton@jcu.edu.au

(Received 20 July 2005; final version received 17 August 2006)

\begin{abstract}
The Intergovernmental Panel on Climate Change has identified Australia as among the developed nations most at risk from climate change effects. Key tourism icon destinations and the tourism sector generally have been identified as being particularly at risk. This paper reports on an interdisciplinary, multi-case study approach to assess tourism stakeholders' knowledge of, and approaches to climate change adaptation, and to explore the potential for building a self assessment toolkit that can be exported to other tourism destinations. This study examined existing knowledge on anticipated biophysical changes and, through primary research (stakeholder interviews and social learning workshops), gauged the expected adaptive approaches of destination communities and the tourism sector to these changes for 2020, 2050 and 2070. The facilitated workshops generated a common set of adaptation strategies across a diverse set of tourist destinations. A key finding from the workshops is that the tourism sector is not yet ready to invest in climate change adaptation because of the perceived uncertainties. Ongoing leadership for such measures were seen to rest with the public sector, especially local authorities. Whether such assessments can be self generated, or require specialist facilitation, remains open to debate.
\end{abstract}

Keywords: Australia, adaptation, climate change, interdisciplinary, toolkit, tourism 


\section{Introduction}

Average annual temperatures across the Australian continent have increased by $0.9^{\circ} \mathrm{C}$ since 1910 (Bureau of Meteorology, 2009). Most of this warming has occurred since 1950, with greatest warming in the east and least in the northwest. Mean maximum and minimum temperatures have increased in this time as has the number of hot days over $35^{\circ} \mathrm{C}$. Since 1950, most of eastern and south-western Australia has become drier, while north-western Australia has become wetter (Bureau of Meteorology, 2009). The number of very heavy rainfall events and the number of wet days have decreased since 1950 in the south and east, but increased in the north. The number of tropical cyclones in the Australian region has decreased in recent decades, largely due to the increasing frequency of El Niños, but the number of severe cyclones has not declined (Hennessey, Webb, Kirono \& Ricketts, 2008).

Climate change is forecast to have a variety of mostly negative economic and non-economic impacts throughout Australia. Projections at the national scale suggest significant increases in mean annual temperatures, coupled with reduced annual rainfall in most places. This will place incredible strain on natural resources and on many industries dependent on these resources for their livelihood, notably agriculture and tourism. In addition, increased risk and intensity of extreme events like bushfires, tropical cyclones, floods and droughts are likely to result in considerable economic costs to the nation (Hennessey et al., 2008).

Becken and Hay (2007) have recently reviewed tourism and climate change at the international scale, identifying the vulnerability of the industry to anticipated future climate change and increasing climate variability. Like many other countries, the Australian tourism industry relies strongly on natural resources, and the industry will be strongly affected by climate change. However, the degree to which climate 
change impacts on regional tourism activities, in terms of economic and noneconomic consequences, depends at least in part on how well the Australian tourism industry, and the natural resources on which it relies, can adapt to climate change.

Several researchers have undertaken community and destination level tourism stakeholder workshops identifying awareness of climate change risks and evaluating specific vulnerabilities for the sector. In some cases the outcomes of such workshops have been published in workshop reports (e.g. Alvord, Long, Pulwarty and Udall, 2008) or technical reports (e.g. Scott and Jones, 2005) while others have been published in journals where some empirical assessment of vulnerability informed by stakeholder workshops was conducted (e.g. Jones, Scott and Abi-Khaled, 2006). An interesting parallel outcome from these earlier workshops, across a diversity of tourism settings and both developed and developing countries, is that the tourism sector is not yet ready to invest in climate change adaptation because of perceived uncertainties. In almost every case, the climate change concerns of the tourism sector revolve around tourist and investor perceptions of their destination's risk of climate change impacts and the impact of climate mitigation policy on travel costs and tourist mobility and eventually reduced tourism demand. Another common finding at such workshops is the industry's reliance on primary role of government for leadership on climate change adaptation.

This paper is a summary of a more detailed technical report, published by the Sustainable Tourism Cooperative Research Centre (Turton, Hadwen and Wilson, 2009). The overall aim of this study was to examine the climate change impacts on the tourism sector in four Australian regional tourism destinations over the next 10, 40 and 60 years (to 2020, 2050 and 2070). The goal of the study was to build a framework to inform and prioritise adaptation strategies which can be undertaken by 
destinations and by tourism businesses. To do this, the climate change vulnerability of each destination was assessed, with a focus on the potential impacts on tourism infrastructure, activities and operational costs. The study was intended to ascertain the adequacy of available data and information to enable research-specific findings.

Case study areas were selected based on known climate change hotspots, as defined by the Intergovernmental Panel on Climate Change (IPCC) Australia / New Zealand working group for the 4th Assessment period (Hennessy, Fitzharris, Bates, Harvey, Howden, Hughes, Salinger and Warrick, 2007). This analysis highlighted six key areas of Australia (Kakadu National Park, Queensland's Wet Tropics and Great Barrier Reef, South East Queensland, Murray-Darling Basin, Alpine Zones, and Southern Western Australia) as key areas of vulnerability. All of these are major tourism regions. To test varying degrees of vulnerability, two of the above (Kakadu, and Tropical North Queensland centred on Cairns) were chosen as the core of the research, with the Blue Mountains (New South Wales) and Barossa (South Australia) also included for alternative assessment areas close to state capitals where tourism is nonetheless a significant contributor to their regional economy. Hence, the four tourist destinations were selected on the basis of their varying perceived degrees of vulnerability to impacts of climate change, with Cairns and Kakadu considered as being highly vulnerable, Barossa and Blue Mountains as vulnerable.

\section{Methodology}

\section{Defining the case study regions}

To facilitate national integration of the results of this study (in addition to identifying regional priorities for adaptation and climate change response), a consistent approach was adopted across the four case study destinations. Each case study region was

initially defined on the basis of the following metrics: 
1) Economic region based on Australian Bureau of Statistics (ABS) statistics and local government areas.

2) Tourist information-numbers, proportion of domestic versus international visitors, seasonality, visitor activities, etc. Data from regional tourism bodies and Tourism Research Australia (2009).

If relating to economic statistical regions was not possible or was particularly difficult, the case study teams were asked to identify how their region sits 'within' a particular ABS statistical region. In addition to the statistical definition of each case study region, case study teams were asked to collate an overview of visitation, seasonality, tourist numbers and activities, as well as some economic information, like expenditures by 'category'. The purpose of this defining process was to characterise each destination, using similar metrics, to facilitate later comparisons and the integration of results at the national scale.

\section{Reviews of secondary data and knowledge at each destination}

After defining the case study regions according to the above criteria, the next step was to undertake rigorous reviews of secondary data and document analyses at each destination. These reviews sought to serve the following key purposes:

\section{Current knowledge of tourism}

To understand current patterns of tourism and the degree to which the sector might adapt to climate change in the future, it was necessary to collate all existing knowledge of tourism activities at each destination. In addition to the metrics mentioned above (numbers, seasonality, activities, expenditure and time), this activity included an assessment of the degree to which knowledge of the tourism sector might limit or aid the nominated approach to the rest of the study. 
Current knowledge of climate change

A review of all currently known climate change impacts at each destination was required to underpin the links between tourism and climate, both as a resource and as a pressure on visitor activities. This process also informed how to best deliver the climate change scenarios to the stakeholders, both during semi-structured interviews and at the stakeholder 'social learning' workshops (see below for more details).

Current knowledge of the degree to which tourism is climate dependent This particular review sought to examine the degree to which the tourism sector was reliant on natural resources and the current climatic conditions of the region, with particular emphasis on how climate change (temperature, rainfall, humidity, sea level, etc) and subsequent changes in environmental resources might affect future tourism patterns and behaviours at each destination. This activity coupled the outcomes of the desktop reviews and asked, in light of the anticipated biophysical changes in each region, the question: so what for tourism? For example, what happens when the freshwater wetlands in Kakadu are flooded with sea water, or what happens when the Great Barrier Reef is bleached more often than in the past? Ultimately, this component of the desktop review aimed to identify how crucial the climate-resource relationship is for tourism at each case study destination.

\section{CSIRO regional climate change projections}

In order to ascertain the climate change sensitivity of the tourism sector at each destination, we commissioned the CSIRO Marine \& Atmospheric Research Division to provide us with regional climate change projections (one for a single location within each destination) for 2020, 2050 and 2070 (Hennessey et al., 2008).

In addition to the general warming and drying observed over the past 50 years, further climate change is likely in the future, due to past and future increases in greenhouse gases (IPCC, 2007). Each of the four case study regions is likely to 
experience warmer conditions over the coming decades, leading to more extremely hot days and fewer extremely cold days. Rainfall changes in the two tropical regions (Kakadu and Cairns) are likely to be small, while decreased rainfall is likely in the other two regions (Blue Mountains and Barossa Valley), especially in winter and spring. Ocean temperatures and sea levels are likely to rise. Tropical cyclones and heavy rainfall events are likely to become more intense in the Kakadu and Cairns regions. Extreme fire weather days are likely to occur more often in the Blue Mountains (Hennessey et al., 2008).

\section{Populating the Visitor-Industry-Community-Environment (VICE) stakeholder grid}

The host community has long been considered as the basis for sustainable tourism development and management (Murphy, 1985; Keogh, 1990; Bramwell and Sharman, 2000; Getz and Jamal 1994, and others). In a systematic study of the goals and constraints on community participation in tourism planning Simmons (1994) noted that the features of tourism planning, namely its integration within a broader (destination) community set of values and planning processes, its changing impact overtime, and the variety of possible perceptions of, or values toward, tourism "suggest that a participation process is required that is ongoing and educational for all parties involved” (p.100). Given both the complexities of tourism and debates surrounding both climate change and potential destination responses a social learning environment (achieved by interactive workshops) was chosen for this study.

In recent times the VICE model has emerged (Tourism Management Institute, 2002; Sleeman and Simmons, 2004; Ministry of Tourism, New Zealand, 2008) as a key framework for organising and balancing participation among key tourism sector stakeholders whereby equal consideration is given to the needs of Visitors, the 
Industry, the local Community and the Environment. We applied the same approach in this study. An example of the VICE model and how to populate it is presented as a grid in Table 1.

The purpose of populating the VICE grid was to identify key stakeholders to be involved either in semi-structured interviews, or the stakeholder workshops, or both. Whilst the suggested membership of the VICE grid in Table 1 was generally applicable across all case study regions, the final make up of these grids varied, depending on: 1) the need to involve stakeholders from more than one environmental sector (e.g. reef and rainforest in Cairns); and/or 2) the need for specific interest groups to be represented (e.g. Indigenous representation at multiple levels for Kakadu). It was also important to note that the stakeholders involved in each VICE group were not there to represent their personal or private business (or community or environmental) interests, but were asked to become involved as a member of the tourism sector that can provide informed discussion on current trends and likely future growth (or otherwise) of the sector.

By engaging the tourism sector across the four VICE 'themes' and using a 'snowballing' approach (i.e. gaining new and additional contacts from the original contacts used to populate the grid), each of the case study teams were able to build a comprehensive list of key stakeholders, including those that should be subsequently invited to become involved in the stakeholder 'social learning' workshops.

\section{Semi-Structured Stakeholder Interviews}

Following the population of the VICE grid at each destination, the next phase of the stakeholder engagement process involved semi-structured interviews, either via phone or face-to-face. These interviews were designed to canvas a wide range of issues across the climate change-tourism area with the key stakeholders, as well as 
identifying the individuals that should be invited to the stakeholder workshops. As mentioned above, given that a snowballing approach was used to establish membership of the VICE grid, the original point of entry into each VICE level may not be the end-point. In other words, the original individuals targeted for semistructured interviews were not always those that ended up being involved in the stakeholder workshops. The purpose of these semi-structured scoping interviews was three-fold:

1) To inform the case study team of existing knowledge, understanding and adaptation to climate change. This was seen as vital information that would aid in determining the best approach for the follow-up stakeholder workshops. Specifically, it was felt that, depending on the knowledge and views of the stakeholders, the scenarios had to be tailored so that they would appeal to all stakeholders, using a common metric or language.

2) To act as a snowballing exercise whereby stakeholders beyond those named in the VICE grid were identified and invited to the social learning workshops

3) To inform, together with the climate projection data from CSIRO, the structure and approach to be taken into the stakeholder social learning workshops.

To ensure that a consistent approach was followed across all destinations, a generic list of questions (Table 2) was formulated for all stakeholders. Importantly, these semi-structured interviews were designed primarily to listen to the concerns of stakeholders, not to educate them on how the study team thought climate change might influence them and the tourism sector in general. Each interview started with an introduction to the study, stating its goals and its sponsors. The introduction also included information about how the interviewee 
was selected and their rights under the research ethics guidelines of the university leading the case study region.

\section{Social learning stakeholder workshops}

Following on from the semi-structured interview process, 'social learning' stakeholder workshops were run at each of the case study destinations to prioritise adaptation strategies and discuss the implications of climate change projections (as provided by CSIRO) anticipated for 2020, 2050 and 2070. The approach involved application of ‘social learning’ theory (see Berkes, 2009; Bull, Petts and Evans, 2008; Pelling, High, Dearing and Smith, 2008), whereby all stakeholders from each VICE component could sit together to discuss the implications of the climate change scenarios on their tourism sector.

Participants were selected via the snowballing approach outlined above to populate the VICE grid. This representation across all groups was critically important to the social learning nature of the workshops, as the aim was for the stakeholders to identify how the sector, and/or particular components of the sector, might be able to implement adaptation strategies in response to the anticipated changes informed by both the CSIRO climate change projections and the existing scientific (e.g. impacts on natural species and ecosystems) and social (e.g. business and/or tourism impacts) knowledge at each destination.

To ensure consistency of the workshop content and social learning environment, one author (Bradley Jorgensen) who has a wealth of experience in leading social learning workshops, was selected as the workshop facilitator for all four destinations. The one day workshops were run in central locations within each case study region (Darwin for Kakadu, Cairns, Katoomba for Blue Mountains and Tanunda for Barossa Valley) between June and October 2008. The number of 
participants at each workshop, excluding the research team, varied between 10 and 20.

\section{Applying the complex climate change science in workshop settings}

Based on the information provided in CSIRO's report (Hennessey et al., 2008), the research team adopted the A1B 'middle-of-the-road' emission scenario as identified by the IPCC (2007). Although recent analyses suggest that the world is currently tracking a much less conservative emission trend, the study team felt that taking a more cautious scenario to stakeholders would engage them in the process of identifying adaptation responses without generating excessive debate (or alarm) about the validity of the projections. As the main purpose of this study has been to identify how the tourism sector can adapt to climate change, it was important for stakeholders to focus on adaptation rather than the climate change science underpinning the projections.

\section{Presenting stakeholders with climate change scenarios}

The challenge of presenting the complexity and uncertainty surrounding climate change projections to a diverse group of stakeholders from the tourism sector, which most likely had varying degrees of knowledge and/or scepticism regarding climate change, was seen as a major methodological hurdle at the onset of this study.

With respect to the scenarios offered to participants of the stakeholder workshops, there had been some discussion of how much pre-knowledge of climate change stakeholders might have and whether a consistent approach was needed to inform stakeholders in each case study area of the predictions coming out of the CSIRO modelling. Ideally, all stakeholders needed to be informed and at a level of mutual understanding of the issues relating to climate change scenarios and what they might mean for the tourism sector. To this end, it was deemed necessary to have a 
brief (20 minute) presentation on climate change, somewhat tailored to the tourism sector in the particular region, at the beginning of each workshop. Importantly, this presentation needed to send a clear and consistent message to all stakeholders across all destinations. Furthermore, stakeholders received handouts of the presentation to take away with them, to aid them in their future discussions and planning activities in relation to global and regional climate changes anticipated over the next 60 years. To achieve the goal of presenting consistent, simple climate science to all stakeholders, the presentation was developed and presented by the same author, Stephen Turton, at each workshop.

For the more detailed information generated by the CSIRO climate modelling team for each region, the major challenge related to how to distil a large number of scenarios down to a smaller number that could be articulated (and responded to) in the workshop setting. Given that the IPCC (2007) uses seven emission scenarios and presents projections at three percentiles (10th, 50th, 90th) for each, coupled with the three time-steps the project team was interested in (2020, 2050 and 2070), there was an overwhelming number of scenarios to choose from. Ultimately, the study team needed to select a single emission scenario that was both somewhat realistic but also not too inflammatory, such that stakeholders would not consider it to be 'reasonable'. The selected scenario also needed to be defendable on the basis of what emission scenario is currently being tracked (the upper end of IPCC predictions) and the concerns and perceptions of the stakeholders engaged in this project. The last thing the project team wanted was to stimulate excessive (and largely unhelpful) debate around the climate science itself, particularly given that this study is about identifying climate change adaptation strategies rather than being about climate change science, 
per se. In the context of the above issues, the A1B 'middle-of-the-road' emission scenario was adopted across all destinations.

\section{Linking climate change projections to biophysical changes at each destination}

Delivering the complex regional climate change projections developed by the CSIRO

(Hennessey et al., 2008) to stakeholders was just the first step in engaging them in discussing the potential impacts of climate change. The next phase, which attempted to link the projections to some anticipated changes in biological and physical aspects of each destination, was a major challenge at most destinations, but was also one that was seen as being particularly important as a means of conveying what changes in temperature and rainfall might mean to how the destinations could 'look' and 'feel' in 2020, 2050 and 2070.

The move from presenting the climate change projections to presenting the biophysical impacts of these projections relied on good underlying science. The Cairns case study team had a wealth of climate change impact research to draw on, both for the Great Barrier Reef and the Wet Tropics Rainforests. Kakadu, the Barossa Valley and the Blue Mountains had considerably fewer published papers outlining biophysical impacts of climate change in their areas. Despite differences in the quality and quantity of climate change studies across the destinations, estimates of biophysical impacts were seen as being highly critical in terms of articulating anticipated changes to the stakeholders attending the workshops. To this end, considerable thought and effort were put into the task of developing a simple but defendable approach to communicating these changes to participants.

The approach adopted across all case study destinations was modelled on that of a recently published paper by Scott, Jones and Konopek (2007), which linked projected climate change to changes in the biophysical components of the landscape 
in a particular national park in Canada. The main benefit of their approach lies with the fact that it effectively removes confusion regarding which emission scenario is being used to generate the biophysical response (in addition to all of the other uncertainties of the model). To explain, their study, which focussed on visitor responses to anticipated climate change in a national park in Canada, offered three dateless scenarios, ranging from minimal changes, to medium change, to moderate change from present conditions. They then categorised these changes against a range of indicators that were likely to represent a common language across all stakeholder groups.

These aspects of visitor expectations can likely be pulled from the desktop review of existing tourism in each case study, such that each destination will be able to provide stakeholders with a range of change scenarios for things they care about. Against these types of environmental change, Scott et al. (2007) provided three scenarios, which were linked to projections from biophysical scientists working on 2020, 2050 and 2080 timelines. However, they did not provide the tourists with these timelines-instead they simply listed the anticipated changes across these three scenarios and asked tourists how they might respond to these 'hypothetical' changes with respect to the likelihood of visitation and the duration of their visits in the future. In many ways, this approach enables us to move away with uncertainty and 'lack of belief' in the climate change scenarios.

Their approach was modified for our four case study regions. Given that the scenarios were being presented to pre-selected workshop participants (not randomly selected tourists) it was decided to include timeframes for the three scenarios (2020, 2050 and 2070). The rationale for this was that the workshop participants had a generally good working knowledge of the climate change issues for their regions, 
albeit at a range of levels. Table 3 provides an example of the three scenarios applied to the Cairns region with respect to anticipated change to the Great Barrier Reef.

\section{Results}

\section{Integration across case studies}

Across all case study destinations, it was clear, both from the science and from the stakeholders engaged in this project, that the anticipated climate change will have both economic and non-economic consequences. Whilst not all of these changes are necessarily negative, many are and represent significant adaptive challenges. In this section, findings from the four case study destinations are integrated in an attempt to identify common themes and issues that may have national relevance. For these issues and strategies, national implementation might be more successful, and realistic, than would a destination/region-focused approach.

To examine the degree to which adaptation strategies were broadly applicable to all destinations examined in this study, all of the strategies nominated were categorised as high priority for each destination to come up with some general themes. Seven theme areas were identified through our analysis of adaptation strategies identified at the four regional workshops. It should also be noted that most of these themes identified by the stakeholders as adaptations to climate change are actually adaptations to climate policy and are probably better described as being more generic to sustainable development rather than being specific to climate change adaptation. This highlights a common finding from this and other comparable studies that tourism stakeholders are not yet ready to invest in adaptation to climate change.

\section{Theme 1: Green}

This theme represents adaptation strategies that were nominated along the 'green and clean’ and 'sustainability' lines, including many water and energy saving initiatives 
that represent best practice for small (and large) businesses. Although many of these strategies are most often thought of as mitigation strategies, many of them were put forward in the context of how the destination could be marketed as a 'green' destination, which represents an adaptation to growing tourist concerns about the tourism 'carbon' footprint.

\section{Theme 2: Data and knowledge}

Adaptation strategies listed under this theme include those that touched on some aspects of data inadequacies, both in terms of businesses and climate change data, and also those which captured the widely held view that there is a real need for increased data collection and improved storage and sharing of data.

\section{Theme 3: Risk and disaster management}

Strategies which sought to improve how disasters are managed fell into this theme. They not only included aspects of resource requirements, but also captured concerns about how the media treats natural disasters and how media-fuelled hysteria, which can damage a destination's image, needs to be better managed by the tourism sector.

\section{Theme 4: Marketing}

Strategies which sought to highlight particular aspects of the destination in brand recognition and marketing initiatives were listed in this theme.

\section{Theme 5: Planning}

Many adaptation strategies revolved around the need for improved and better informed planning of both built and natural environments. These strategies fell into the planning theme.

\section{Theme 6: Community}

Community themed adaptation strategies revolved around the idea of local identity, the need to produce food locally (and support it), and the need for strong community- 
government relationships. Only two of the destinations (Cairns and Barossa Valley) had community-themed adaptation strategies, which not only highlights the local residents' attachment to these destinations, but also the feeling that they would be willing to fight for the businesses and tourism market in these regions.

\section{Theme 7: Resources}

As for planning, many adaptation strategies were nominated that focused on the management of resources, both built and natural, and the need for additional resources (in both of these areas) to support the implementation of adaptation strategies.

Despite being generally applicable across all destinations, few of the seven themes were nominated by stakeholders from all four destinations. Indeed, only the green theme had adaptation strategies nominated from all case studies. Adaptation strategies were nominated by three of the destinations in four other themes, namely data and knowledge, disaster management, marketing and planning. Community themes were only picked up by stakeholders in the Cairns and Barossa Valley destinations, and adaptation strategies relating to the management of (and access to) resources were only nominated in the Cairns and Kakadu destinations. Some of these trends in theme area membership, across destinations, are likely to be driven by similarities and differences among the destinations and the nature of the tourism sector within these regions, as discussed in more detail below.

The appeal of green strategies was highlighted by the fact that all four destinations had at least three adaptation strategies relating specifically to the sustainable use of energy and water. Although these strategies often represent operational best practice and are also mitigation measures, there is also an obvious link between improved performance and the desire, shared across all destinations, to be marketed and perceived as being a 'green' destination. This latter point is reflected 
in the fact that all destinations highlighted this green marketing as one approach that might enhance the tourism industry's capacity to better position itself in a climate change affected marketplace.

\section{Capacity for adaptation strategy adoption and implementation}

In all destinations, the stakeholder workshops revealed considerable institutional, legal, community and resource limitations that inhibit, or are at least perceived to inhibit, the timely implementation of adaptation strategies. Interestingly, this is despite the fact that all destinations nominated sustainable use of resources, especially water and energy, as an adaptation strategy which clearly represents best practice and has been shown to save businesses lots of money. Nevertheless, there were numerous and often-articulated barriers to implementing the suggested adaptation strategies, including:

- The scale and uncertainty surrounding climate change projections.

- Communication within and between regional and National bodies.

- Concerns regarding the capacity of small and medium enterprises to adapt, relative to governments and larger operators.

The following sections will address each of these areas.

Uncertainty and scepticism surrounding climate change projections Numerous stakeholders indicated that they were sceptical about the perceived role that human activities have had in stimulating climate change, and/or that the geographical scale (super-regional at best) and uncertainty in climate change projection modelling resulted in considerable uncertainty in their minds about how much they were willing to invest (intellectually and economically) in climate change adaptation. Although scepticism within the workshop groups was generally quite low, workshop participants commented that there was enough scepticism in the community 
to prohibit rapid and significant adaptation. Not all stakeholders were concerned about the scale of climate change projections and but many recognised the fact that as a global phenomenon there will be no escaping from climate change. Nevertheless, in terms of evaluating priority actions within their destination, many participants felt that it would be necessary for regional-scale projections to be created to assist with the planning and response process.

Despite uncertainty and concern regarding the science of climate change and how it is likely to impact regional communities and industries, all stakeholders recognised the threat that climate change (or even media relating to climate change) poses to the regional communities that give tourism in the case study destinations its particular character. In this context, tourism demand could be significantly reduced simply by perceived changes; hence the above call for more regionally relevant and up-to-date climate information. Coupled with stakeholders' concerns about media coverage of climate change and natural disasters, it seems that climate change is, and will continue to be, a major issue confronting tourism in regional Australia.

\section{Communication and community involvement}

Although not all destinations examined in this study had tight-knit communities, there was an overwhelming view that local communities and stakeholders are required to be heavily involved in the planning and implementation of adaptation strategies. Whilst resources frequently came up as a limiting factor in this local 'grass roots' approach, few participants felt that a top-down national approach would work for all destinations. Clearly, there was a consistent view that locals know their destinations best and they, therefore, should be the ones coordinating and implementing adaptation. As one respondent commented, 'local communities are... central to the adaptation of the region as they provide the raw materials from which the tourist 
experience is packed, marketed and sold.' Adding to this view was the sentiment that a national approach would not adequately consider the importance of the local community in creating, influencing and contributing to the sense of place and, indeed, making tourism possible.

Communication and inclusion also appear to be important features of how a successful adaptation plan could be implemented. Many respondents expressed their concern about the number and overlap between climate change research projects, initiatives and granting schemes. Specifically, some stakeholders had been involved in multiple climate change workshops and felt that more coordination and communication among (and within) sectors like the government (at all levels), the tourism industry, local community groups and researchers was required.

Adaptive capacity of tourism - an industry built around small and medium enterprises One of the major perceived limitations to adaptation within the tourism sector is the high proportion of small and medium enterprises (SMEs) that characterise regional tourism. Specifically, a lot of concern revolved around the fact that these smaller enterprises are operating on small overheads with little or no capital or capacity to implement major adaptation strategies. Furthermore, very few SMEs are able to plan on timeframes longer than a couple of years, and as a result, making changes now, which will cost something, with a view to threats that may or may not eventuate in 10 , 20 or 50 years time, is not something that many of these smaller operators are willing (or able) to do. Similar findings have been found for the ski tourism sector (e.g. Scott and McBoyle, 2007).

In contrast, the overwhelming view across destinations was that bigger operators were more likely to be planning and implementing adaptation strategies now, as they have more resources and may have a responsibility to their stakeholders 
to manage the risks of climate change impacts on business operations and bottom lines.

Adaptation strategy adoption

The adoption of adaptation strategies will require some, if not all, of the following:

- Confidence that the climate is really changing and that increased variability in climate is part of the process.

- Motivation to avoid risk or to take up opportunities.

- Demonstration of new technologies.

- Transitional and legislative support from government.

- Resources from government and private stakeholders.

- Effective monitoring and evaluation — climate change is a moving target.

\section{Future actions applicable to all case study regions}

Despite the concerns and limitations outlined above, climate change adaptation is necessary, as a precautionary principle, in all four case study destinations. Likewise, adaptation to climate variability under current conditions is an ongoing issue in these destinations as the industry has existing adaption plans for extreme events (e.g. tropical cyclones, bush fires, floods and droughts). Whilst many of the adaptation strategies outlined in this paper represent excellent business and community opportunities (best practice) and can also serve as mitigating strategies, there are still many additional strategies that require further investigation, both in terms of their adaptive potential and their capacity to be implemented. Furthermore, significant science and other knowledge gaps represent risks in the adaptation approach, so more funding is required to examine other components of the tourism-climate change space. In addition to further research on areas already touched on in this study, there are 
substantial additional areas of research and policy effort that require attention in the light of the findings, or limitations, of this scoping study.

Adaptation is an on-going process and Australians have proven resilient over time to significant natural variation in climate. Enhancement of this adaptive capacity in the face of increasing climate variability as described in this report must, in the first instance, build on this inherent capability.

The strategies required to address both the overarching adaptive capacity and the range of individual climate change impacts need to be tailored for each type of business and within each region. The majority of tourism businesses are SMEs, made up of many different types of products, and the long term impacts of climate change may be quite different from one product to another. Some businesses have built infrastructure which may be very costly or difficult to upgrade or alter, and some are mobile operators that have the capacity (over time) to amend tour programs in response to destination changes. Some have no physical assets (e.g. cultural walks and talks) that could more easily transition what is being interpreted and where the product might be situated, possibly at little or no cost.

Because tourism is one of a number of activities that occurs within communities — all of which draw on natural resource capacities and local infrastructure—workshop participants recognised that adaptation for tourism destinations should be part of the general community management processes. It is State and Local Authorities that hold statutory risk management responsibilities—and need to accommodate the ongoing integration of tourism activities within their broader mandate. Climate change adaptation (and to a lesser extent mitigation $\{$ which might better be applied to the industry as a whole\}) must be incorporated as part of the ongoing processes of 'destination management' and (community /resource) 'risk 
management'. To develop and advocate tourism focus, lead tourism agencies (State Tourism Organisations State Tourism Industry Councils, Regional Tourism

Organisations, Local Tourism Organisations) need to be proactive in integrating destination management into Local Government statutory planning processes. The VICE model (Table 1) has provided a simple framework for integrating stakeholder views into such processes.

\section{Discussion}

Recommendations for application of the methodology to additional tourist destinations - a climate change destination 'toolkit'

The experiences in applying the methodology provided in this study would obviously be interesting and relevant to any individuals or groups hoping to undertake a similar analysis of climate change impacts and adaptation in their regions. To this end, it is thought that other interested parties, from tourism and other destinations, will benefit considerably from the findings of this study. Indeed, the high level of overlap in nominated adaptation strategies, at least across the similar destinations in this study, will serve as a good pointer for new destinations, as interested parties will no doubt be able to identify lots of relevant adaptation strategies just by reading through those that are listed in this study under the seven thematic areas.

Although the approach outlined in this study is relatively simple and easy to follow, local experts can provide significant and highly relevant additional information. To this end, it is recommended that regional authorities hoping to apply the methodology seek out appropriate expert advice and support, whether it be in the form of climate science and regional projections, tourism statistics, economic data collation and modelling, and/or assessment of relevant stakeholders that need to be engaged in the interviews and workshops. 
An additional consideration in the context of whether a 'toolkit' could be generically applied across a wide variety of destinations is that conflict may arise when topics covered in this study are presented, or challenged. This will be dependent upon the stakeholder mix, the quality of the information provided and the degree of scepticism or cynicism among the participants. While none of these problems were experienced to any great degree in this project, it may be that a regional tourism organisation may not be the best facilitator of the approach in light of the views held by stakeholders regarding the purpose or scope of such entities. In these instances, an independent and potential national-in-scope facilitator, or lead team, may be required to provide a less locally biased-approach (or at least one perceived to be unbiased) to the generation of adaptation strategies.

Finally, it is evident that the approach outlined in this study is also likely to be highly relevant and applicable to interest groups outside of the tourism sector, particularly those where multiple and sometimes competing stakeholders are concerned. Certainly, regions with complex and significant mining, agriculture, tourism and/or cultural identities may find the VICE grid approach to be a useful framework to identify and engage all relevant parties in discussions of adaptation strategies and capacities within the region.

\section{Who can run this process at new destinations?}

The approach taken in this study is logical, straightforward and relatively easy to apply. As a result, the approach is likely to be generically applicable to sectors beyond the tourism sector. Local agencies or individuals wishing to implement this approach may do so as the methodology currently stands (at least for the non-economic component of the study), but who that group or individual is will likely be different for each new destination. One suggestion has been for substantial local government 
involvement, since they invest heavily in tourism at the regional scale and, increasingly, also have climate change and/or sustainability officers. However, depending on the size of the region/destination and the sectors involved in the interviews and their relationships to the local council, these local government bodies may not be the best drivers of this process. Indeed, the study team's experience has been that implementation of the approach used in this study will ultimately be dependent on the will of all of the relevant parties (across the VICE grid). It is suggested that the level of scepticism and engagement of these parties is best assessed during the semi-structured interview phase of the project, whereby the lead individual or organisation can determine the need, or otherwise, for an independent body or facilitator to become involved in the process. From the study team's experience, some destinations have good links across VICE grid groups and the trust that already exists in these relationships will likely enable a single agency to run the process. However, in destinations where vested interests or high levels of scepticism exist, it may be in the best interests of the project goals to engage with an independent facilitator and/or research team to ensure that all stakeholders feel equally engaged and are willing to contribute to the process without fear of misrepresentation or distrust.

At this point it should be highlighted that decisions on who should lead the adaptation process in new destinations do not need to be made before the process starts. Indeed, one of the purposes of the semi-structured interview phase is to identify whether engagement, across all VICE grid groups, is sufficient to get the right individuals, with the right attitudes, engaged in the project and its intended outcomes. The person or persons conducting these interviews should therefore be able to determine whether independent facilitation will be required at this early stage of the process. For this to be achieved it may be necessary for the interviewer to be trained 
up to a level at which informed and objective conclusions about this matter can be made. In cases where it is deemed that independence is required, it may be that a national body like the Sustainable Tourism Cooperative Research Centre, (and certainly not a parochial regional body), may provide one option for outsourcing such activities.

\section{Knowledge gaps and future research}

The findings and the limitations of this study have identified a number of areas that require further research effort to enhance the development and discussion of climate change adaptation in regional Australia and elsewhere (Table 4). Some of the research needs revolve around the desire, among interview and workshop participants, for improved regional projections and predicted impacts on biophysical components of the landscape. Others are more socioeconomic in nature and include aspects of tourism demand, including how visitors (tourists), communities and economies are likely to respond to climate change.

\section{Conclusions}

This paper reported on an interdisciplinary, multi-case study approach to assess tourism stakeholders' knowledge of, and approaches to climate change adaptation, and explored the potential for building a self assessment toolkit that can be exported to other tourism destinations. We examined existing knowledge on anticipated biophysical changes and, through primary research (stakeholder interviews and social learning workshops), gauged the expected adaptive approaches of destination communities and the tourism sector to these changes for 2020, 2050 and 2070. The facilitated workshops had the objective of raising awareness of climate change risks and identifying and evaluating specific vulnerabilities for the sector in Australia. 
A key finding from the workshops is that the tourism sector is not yet ready to invest in climate change adaptation because of the perceived uncertainties. This is evidenced by the fact that most of these themes identified by the stakeholders as adaptations to climate change are actually adaptations to climate policy and are probably better described as being more generic to sustainable development rather than being specific to climate change adaptation.

\section{Acknowledgements}

The Sustainable Tourism Cooperative Research Centre (STCRC), an Australian Government initiative, and the Department of Resources, Energy and Tourism (DRET) funded this research. We acknowledge the following people who have contributed to this study: Anna Boustead, Bruce Hayllar, John Merson, Blue Mountains World Heritage Institute staff, Maureen Rogers, Peter Hayman, Graham Brown and Jenny Davies. We especially thank the many VICE participants across the case study regions and those who participated in the semi-structured interviews.

\section{References}

Alvord, C. P., Long, R., Pulwarty, \& Udall, B. (2008) Climate and Tourism on the Colorado Plateau. Bulletin of Meteorological Society May 2008, 672-675.

Becken, S. \& Hay, J. (2007) Tourism and Climate Change: Risks and Opportunities. Channel View Publications.

Berkes, F. (2009) Evolution of co-management: Role of knowledge generation, bridging organizations and social learning. Journal of Environmental Management, 90, 1692-1702.

Bramwell, B. \& Sharman, A. (2000) 'Approaches to Sustainable Tourism Planning and Community Participation’. In: Richards, G., and Hall, D (eds) Tourism and Sustainable Community Development,) Routledge UK, pp 17- 35.

Bull, R., Petts, J., \& Evans, J. (2008) Social learning from public engagement: dreaming the impossible? Journal of Environmental Planning and Management, 51, 701-716. 
Bureau of Meteorology (2009) Bureau of Meteorology Website, http://www.bom.gov.au/

Getz, D. \& Jamal, T.B. (1994) The environment-community symbiosis: a case for collaborative tourism planning, Journal of Sustainable Tourism, 2, 152-173.

Hennessy, K., Fitzharris, B., Bates, B.C., Harvey, N., Howden, M., Hughes, L., Salinger, J. \& Warrick, R. (2007) 'Chapter 11, Australia and New Zealand’. In: M.L. Parry, O.F. Canziani, J.P. Palutikof, P.L. van der Linden \& C.E. Hanson (Eds) Climate change 2007: Impacts, adaptation and vulnerability. Contribution of working groups II to the fourth Assessment Report on the Intergovernmental Panel on climate Change. Cambridge University Press, Cambridge, UK. pp. 50740.

Hennessy, K., Webb, L., Kirono, D. \& Ricketts, J. (2008) Climate change projections for five Australian tourism regions. CSIRO, Melbourne, Australia.

Intergovernmental Panel on Climate Change (2007) ‘Summary for Policymakers’. In: M.L. Parry, O.F. Canziani, J.P. Palutikof, P.L. van der Linden \& C.E. Hanson (Eds) Climate change 2007: Impacts, adaptation and vulnerability. Contribution of Working Group II to the Fourth Assessment Report of the Intergovernmental Panel on Climate Change. Cambridge University Press, Cambridge, United Kingdom and New York.

Jones, B., Scott, D.\& Abi-Khaled, H. (2006) Implications of climate change for outdoor event planning: a case study of three special events in Canada's Capital Region. International Journal of Event Management, 10, 63-76.

Keogh, B. (1990) Public participation in tourism planning. Annals of Tourism Research, 17, 449-465.

Ministry of Tourism, New Zealand (2008) 'Tourism Planning Toolkit', http://www.tourism.govt.nz/Our-Work/Local-Government-/Tourism-PlanningToolkit/

Murphy, P. E. (1985) 'Tourism a Community Approach'. Methuen, New York.

Pelling, M., High, C., Dearing, J., \& Smith, D. (2008). Shadow spaces for social learning: a relational understanding of adaptive capacity to climate change within organisations. Environment and Planning A, 40, 867-884.

Scott, D. \& McBoyle, G. (2007) Climate change adaptation in the ski industry. Mitigation and Adaptation Strategies to Global Change. 12, 1411-1431. 
Scott, D \& Jones, B. (2005) 'Climate Change \& Banff National Park: Implications for Tourism and Recreation'. Report prepared for the Town of Banff. Waterloo, ON: University of Waterloo, Canada.

Scott, D., Jones, B. \& Konopek, J. (2007) Implications of climate and environmental change for nature-based tourism in the Canadian Rocky Mountains: A case study of Waterton Lakes National Park. Tourism Management, 28, 570-579.

Simmons, D.G. 1994. Community participation in tourism planning. Tourism Management, 15, 98-108.

Sleeman, R. \& Simmons, D.G. (2004). 'Tourism Planning Toolkit for Local Government’. Electronic Book published at http://www.tourism.govt.nz/tourismtoolkit/index.htm.

Tourism Management Institute (2002) 'Destination Management Handbook'. downloaded from http://www.insights.org.uk/destinationmanagementguide.aspx $21 / 12 / 2009$

Tourism Research Australia (2009) 'Local Government Area Profiles’, http://www.tra.australia.com/ regional.asp?sub=0159

Turton, S., Hadwen, W. \& Wilson, R. (Eds) (2009) The impacts of climate change on Australian tourism destinations: developing adaptation and response strategies a scoping study. Cooperative Research Centre for Sustainable Tourism Pty Ltd, Gold Coast, Australia. 266pp.

Wilson, R. F. \& Turton, S. M. (2010) The impact of climate change on reef-based tourism in Cairns, Australia - adaptation and response strategies for a highly vulnerable destination. In: A. Jones \& M. Phillips (Eds) Disappearing Destinations: Climate Change and the Future Challenges for Coastal Tourism. CABI Publications, UK. (In press). 


\section{Short biographical notes on all contributors}

Stephen Turton is a professor in the School of Earth and Environmental Sciences at Cook University in Cairns Australia. His research interests include climatology, rainforest ecology and natural resource management.

Tracey Dickson is senior research fellow in the Centre for Tourism Research, Faculty of Business and Government, University of Canberra, Australia.

Wade Hadwen is a research fellow in the Australian Rivers Institute at Griffith University, Australia. Wade is an aquatic ecologist by training; much of his research examines aspects of human interactions with the natural environment.

Bradley Jorgensen is senior research fellow at the Centre for Sustainable Regional Communities, La Trobe University, Australia. His research interests include sense of place, trust and fairness in natural resource management decision-making, contingent valuation, subjective well-being, and environmental attitudes and behaviours.

Tien Pham is a lecturer at the School of Tourism and a research fellow at the School of Economics at the University of Queensland, Australia. His research interests are in regional modelling including Tourism Satellite Account and the Computable General Equilibrium (CGE) economic modelling.

David Simmons is professor and director of research for the Sustainable Tourism Cooperative Research Centre at Griffith University’s Gold Coast Campus, Australia.

Pascal Tremblay is the Chair of Tourism at Charles Darwin University; his research interests include aspects of economic, regional and Aboriginal development linked with tourism as well as industry collaboration, wildlife and the economics of protected areas.

Robyn Wilson is a postdoctoral research officer in the Australian Tropical Forest Institute at James Cook University working on identifying adaptation strategies to climate change for tourism and forest industries. 
Table 1: The VICE (Visitor, Industry, Community, Environment) grid approach to identify key tourism stakeholders for the semi-structured interviews and stakeholder social learning workshops

\begin{tabular}{|c|c|c|c|c|}
\hline & Visitors & Industry & Community & Environment \\
\hline Policy & $\begin{array}{l}\text { Regional tourism } \\
\text { organisation; } \\
\text { visitor } \\
\text { information } \\
\text { centre }\end{array}$ & $\begin{array}{l}\text { State tourism } \\
\text { organisation; } \\
\text { accommodation } \\
\text { operator or } \\
\text { association }\end{array}$ & $\begin{array}{l}\text { Elected Member } \\
\text { of Parliament } \\
\text { (state or federal) }\end{array}$ & $\begin{array}{l}\text { Land } \\
\text { management } \\
\text { agency (e.g. state- } \\
\text { based EPA) }\end{array}$ \\
\hline Practice & Tour specialist & $\begin{array}{l}\text { Large } \\
\text { accommodation } \\
\text { provider }\end{array}$ & $\begin{array}{l}\text { City/regional } \\
\text { planner }\end{array}$ & $\begin{array}{l}\text { City/regional } \\
\text { environment } \\
\text { manager }\end{array}$ \\
\hline Practice & $\begin{array}{l}\text { Other tour } \\
\text { operator }\end{array}$ & $\begin{array}{l}\text { Ecotourism peak } \\
\text { body }\end{array}$ & $\begin{array}{l}\text { Community board } \\
\text { member }\end{array}$ & $\begin{array}{l}\text { Non-government } \\
\text { organisation } \\
\text { (NGO) }\end{array}$ \\
\hline
\end{tabular}


Table 2: The generic semi-structured interview questions asked of all respondents

\begin{tabular}{|l|l|}
\hline \multicolumn{2}{|l|}{ Question } \\
\hline 1 & $\begin{array}{l}\text { Are people in [the case study region] talking about changing weather patterns and } \\
\text { climate change? } \\
\text { [If yes, prompt... How is it being talked about and by whom?] } \\
\text { [If no, prompt... Are there other issues that people see as important for tourism in } \\
\text { the region?] }\end{array}$ \\
\hline 2 & $\begin{array}{l}\text { What types of positive and negative effects do you think climate change will have } \\
\text { on tourism in [the case study region]? } \\
\text { [Prompt consequences of effects on natural environment, infrastructure, activities, } \\
\text { operational costs, community life etc...] }\end{array}$ \\
\hline 3 & $\begin{array}{l}\text { How do you think tourism [the case study region] may respond or adapt if the } \\
\text { climate changes? } \\
\text { [Prompt adaptation strategies which could be adopted by interviewee (what } \\
\text { would you do) or others (what would others do) to adapt to negative impacts } \\
\text { and/or take advantage of positive impacts.] }\end{array}$ \\
\hline 4 & What actions (from Q.3) are happening now or need to happen now? \\
\hline 5 & $\begin{array}{l}\text { Do you believe that [the case study region] can adapt to the likely effects of } \\
\text { climate change? }\end{array}$ \\
\hline 6 & $\begin{array}{l}\text { What timeframes are required to properly respond and adapt to climate change in } \\
\text { [the case study region]? }\end{array}$ \\
\hline 7 & $\begin{array}{l}\text { What do you need to know in order for the tourism sector in your region to adapt } \\
\text { to climate change? } \\
\text { [Prompt for knowledge/understanding of tourism's reliance on human resources, } \\
\text { infrastructure, the natural environment, communities etc and the likely effects of } \\
\text { climate change on these components] }\end{array}$ \\
\hline 8 & $\begin{array}{l}\text { Are there other individuals or organisations that you think we should be speaking } \\
\text { to as part of our interviewing process? }\end{array}$ \\
\hline 9 & $\begin{array}{l}\text { Would you be interested in participating in a workshop in the next few months to } \\
\text { discuss climate change and tourism with other representatives from the tourism, } \\
\text { business, environment and community sectors? } \\
\text { [If no, prompt... Is there some other way that you would like to be involved in } \\
\text { this project?] }\end{array}$ \\
\hline
\end{tabular}




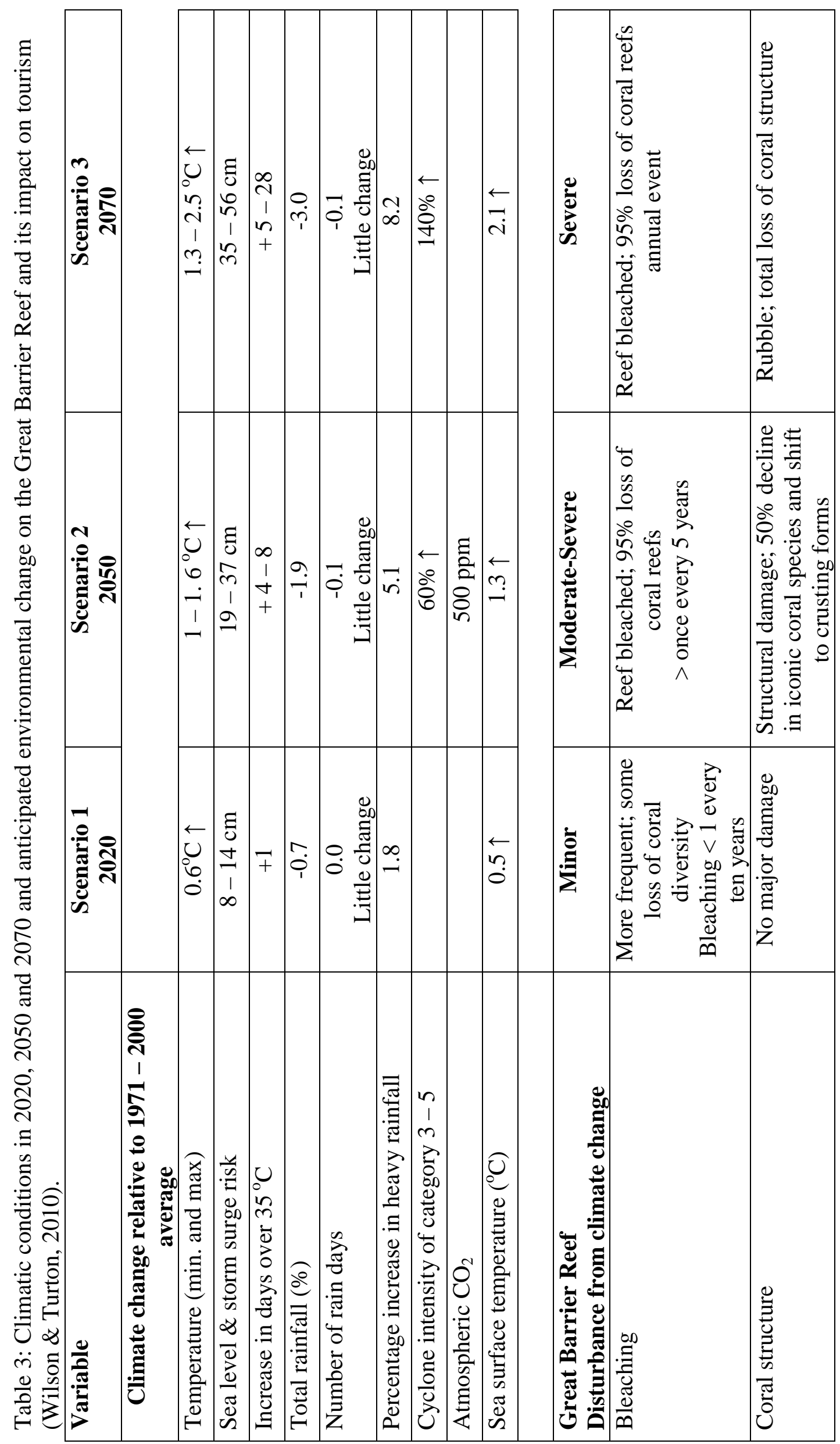




\begin{tabular}{|c|c|c|c|c|c|c|}
\hline 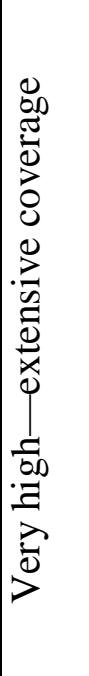 & 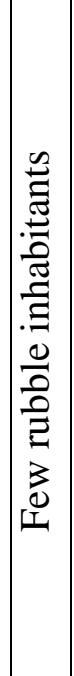 & 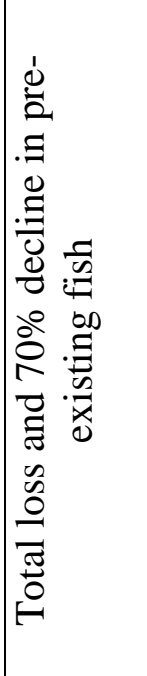 & 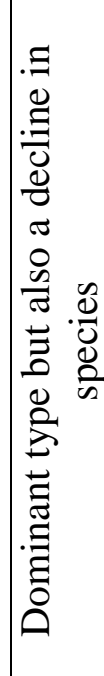 & 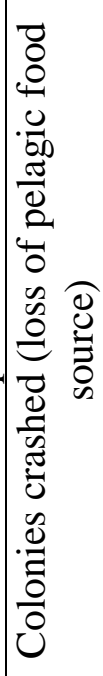 & 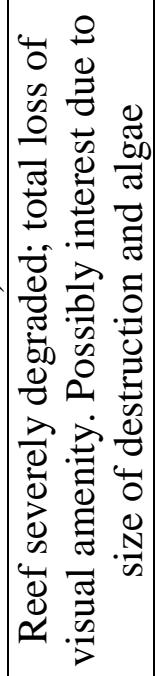 & | \\
\hline 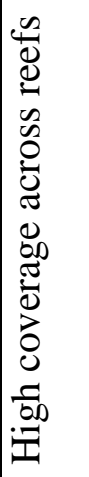 & 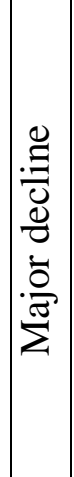 & 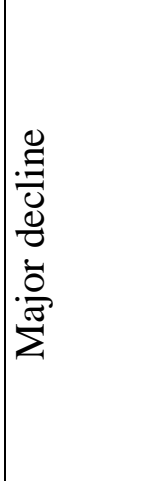 & 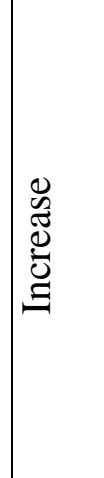 & 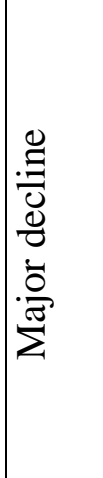 & 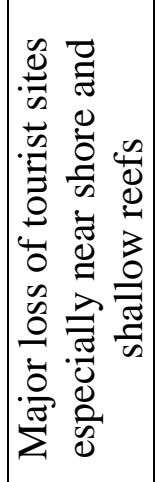 & $\frac{3}{3}$ \\
\hline 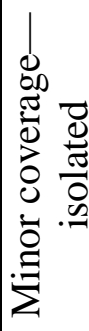 & 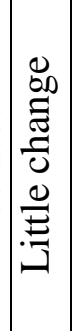 & 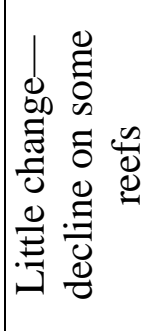 & 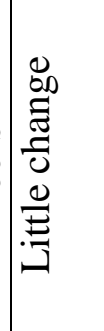 & 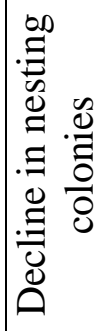 & 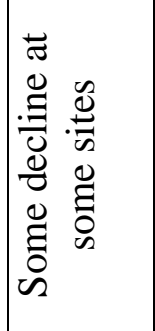 & 竞 \\
\hline 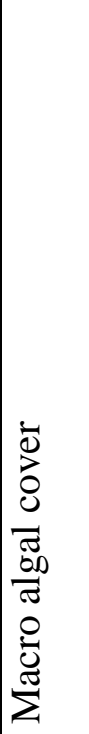 & 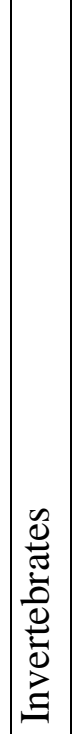 & 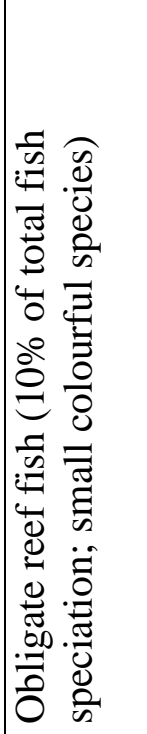 & 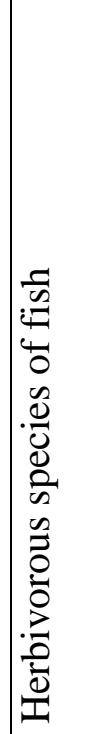 & 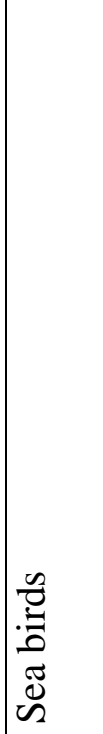 & 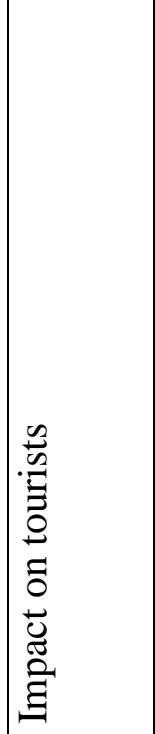 & 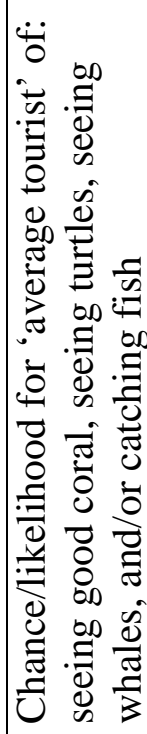 \\
\hline
\end{tabular}




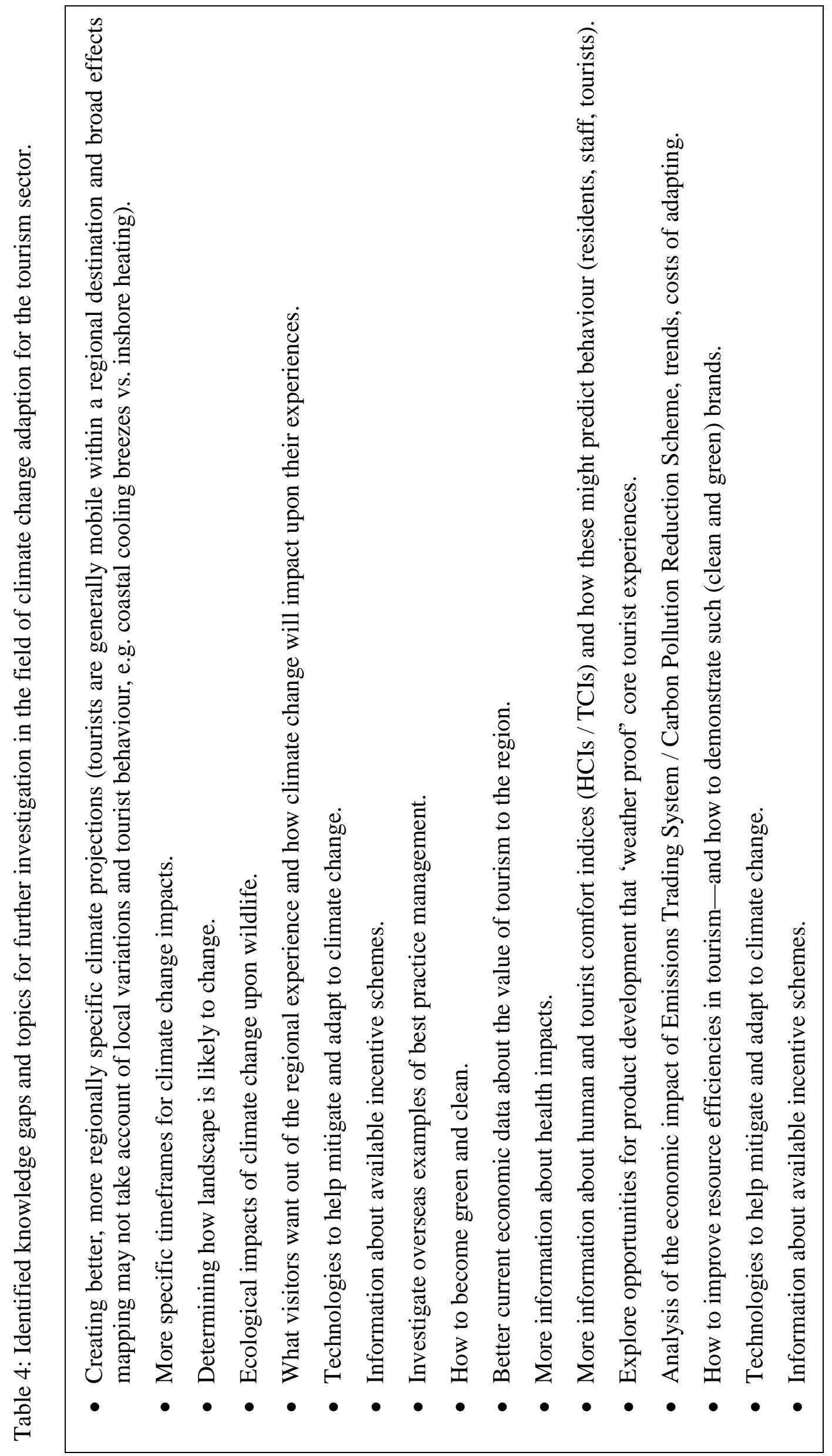




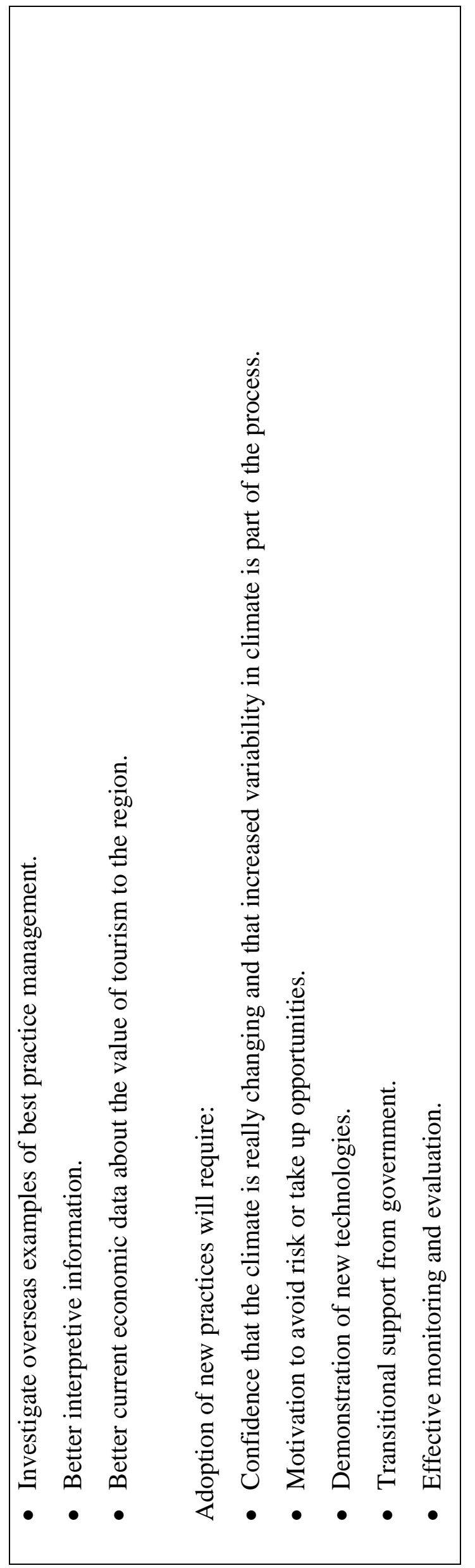

